\title{
Production and molecular composition of Burkholderia pseudomallei and Burkholderia thailandensis biofilms
}

\author{
Udoka Okaro $^{1}$, Sherry Mou ${ }^{2}$, and David DeShazer ${ }^{2}$ \\ ${ }^{1}$ United States Army Medical Research Institute of Infectious Diseases \\ ${ }^{2}$ United States Army Medical Research Institute of Infectious Diseases
}

May 18, 2021

\begin{abstract}
Biofilm communities cause many infectious diseases. Biofilms are diverse microbial species found either attached to a surface or aggregated into an extracellular matrix. Bacteria form biofilms as a default mode of growth or as a response mechanism to environmental conditions like stress. As such, biofilm strains are increasingly virulent causing a wide variety of chronic persistent diseases, are typically antibiotic-resistant and known to improve host mortality rate. Most biofilms contain polysaccharides, proteins, extracellular DNA (eDNA), RNA, and water. Determining and quantifying the major components of a biofilm may indicate an appropriate treatment for biofilm eradication. Burkholderia pseudomallei is a Gram-negative, motile bacillus typically found in surface water and/or soil in endemic regions. It is the etiologic agent of melioidosis and is capable of forming both surface adherent and air-liquid interface biofilms (pellicle) in broth cultures. This study evaluates the components of established biofilms using B. pseudomallei and Burkholderia thailandensis, a closely related nonpathogenic species. Using assays, fluorescent dyes and microscopy, we quantified the major components of biofilms produced by five genetically related B. pseudomallei strains and compared them to B. thailandensis E264. Our data show that biofilm produced by the B. pseudomallei 1026b derivatives and B. thailandensis E264 significantly differ. The molecular composition of the surface adherent biofilm is similar to the molecular composition of the air-liquid pellicle. Finally, the eDNA quantity biofilm produced by JW270 which bears a CPS I deletion, is significantly increased in comparison to 1026 and Bp82 biofilm.
\end{abstract}

\section{Introduction}

Biofilms are a self-secreted extracellular matrix produced by microbes to mediate adhesion and survival of microbial cells, especially in hostile environments. Biofilms can either be formed on an abiotic surface (surface adherent biofilm) or at the air-liquid interface (pellicle) [1]. Some functions of a biofilm include cell to cell communication, storage and recycle of nutrients, horizontal gene transfer, protection from environmental stressors and, protection of bacterial cells from phagocytic engulfment by host mammalian cells [2]. To form a biofilm, single cells adhere to a surface, aggregate into colonies, and export components of the biofilm. Single cells are dispersed from a mature biofilm to aggregate and form new biofilms [2]. Biofilms can colonize or thrive on most surfaces and is harmful to the host organism accounting for about $80 \%$ of microbial infection [3]. Biofilms are extremely difficult to eradicate due to their increased tolerance for antimicrobials and antibiotics $[4,5]$.

Burkholderia pseudomallei (B. pseudomallei) is a Gram-negative bacteria known to form both surface adherent biofilms and pellicles [6-8]. It is the causative agent of melioidosis, a disease endemic throughout Southeast Asia and northern Australia with an overall death rate of $16 \%-18.4 \%$ [9]. B. pseudomallei is found in a wide range of ecological niches such as soil, surface water and roots of legumes and can survive under a variety of environmental conditions indicating the ability to quickly sense and respond to environmental changes such as temperature, through specific survival mechanisms. $[10,11]$. Human inoculation is typically through inhalation or inoculation through skin abrasions but a handful of human-human transmission cases 
have been reported [12]. There is no approved melioidosis vaccine and treatments rely on high doses of antibiotics which may be ineffective [13-15]. About $10 \%$ of melioidosis patients relapse [16]. A typical relapse in bacteremia is linked to the ability of the bacteria to persist in a colonized niche like a biofilm within the host. Higher mortality rate and chronic inflammation infections in host cells are also linked to biofilm-forming strains $[17,18]$. To survive under stressed environments like the human host, B. pseudomallei modifies the expression of virulence genes like the Bsa type III secretion system [19], metabolic and motility genes [20], and biofilm genes [21]. A variety of genes have been implicated in B. pseudomallei biofilm processes like adhesion [22] and eDNA secretion which facilitate biofilm formation [23, 24]. However, the complete pathways for genes involved in the formation of biofilms and/or the secretion of molecules are not clearly understood. Numerous studies have shown that eDNA is released from viable cells and required for biofilm formation and structure inBurkholderia . [23, 25, 26]. Burkholderia species also produce and export numerous outer membrane polysaccharides and proteins [27-29]. Recent studies have suggested that biofilms can be dispersed by enzymes that target biofilm constituents [30]. Biofilm dispersal using enzymes is also suggested as the mechanism by which planktonic cells are liberated from a mature biofilm to colonize a new site/surface [31]. Supernatants of non-dispersed biofilms lack degradative enzymes and endonucleases were expressed in dispersedPseudomonas aeruginosa cells [31, 32]. These enzymes target polysaccharides, proteins, lipids, and eDNA, the core architectural composition of biofilms $[2,30]$. Thus, degradative enzymes have been employed to degrade biofilm components in bacteria to initiate dispersal and liberate planktonic cells which are susceptible antibiotics. Dispersin B, an enzyme that hydrolyzes poly- $N$-acetyl glucosamine (PNAG) polysaccharide, inhibited Acinetobacter baumannii pellicle formation, suggesting that polysaccharides contribute to pellicle formation [33]. DNase and proteinase $\mathrm{K}$ are known to decrease the amount of biofilms formed by B. pseudomallei and P. aeruginosa, respectively [25, 34].

In this study, we investigated the biofilms produced by virulent and avirulent Burkholderia strains, including B. thailandensisE264 [35], B. pseudomallei 1026b [36] and four mutants derived from 1026b (1026b [?]asd [37], Bp82 [38], DD503 [39] and JW270 [40]). B. thailandensis E264 is a nonpathogenic soil saprophyte that can be grown and manipulated at biosafety level 2 (BSL-2), but B. pseudomallei 1026b is a virulent human isolate that must be handled in a high containment BSL-3 laboratory. B. pseudomallei 1026b [?]asd harbors a deletion mutation in the gene encoding aspartate-semi aldehyde dehydrogenase and is unable to grow on media without diaminopimelate (DAP) supplementation [37]. B. pseudomallei Bp82 is auxotrophic for adenine and thiamine due to a deletion mutation in the purM gene [38]. 1026b [?]asd and Bp82 are both avirulent in mice and have been removed from the CDC select agent list. DD503 is a 1026b derivative that harbors a deletion of the genes encoding the AmrAB-oprAantibiotic efflux pump and is virulent in animal models of infection and must be worked with at BSL-3 [39]. B. pseudomallei JW270, a DD503 derivative, contains a deletion of the $w c b$ gene cluster encoding capsular polysaccharide CPS I, a homopolymeric polysaccharide required for virulence [40].

We employed glucosidase, proteinase $\mathrm{K}$ and DNase to disperse/eradicate the biofilms produced by these Burkholderia strains and examined the molecular composition of both surface-adherent and pellicle biofilms. While we found no difference in biofilm formation between B. pseudomallei strains and B. thailandensis, there were striking differences in biofilm polysaccharide, protein and eDNA content. We propose that the different biofilm composition observed between the B. pseudomallei derivatives and B. thailandensis may allow a better understanding of Burkholderiabiofilm biogenesis and regulation. We propose that the genetic manipulations between the 1026b derivatives is responsible for the difference in biofilm composition.

\section{Results}

\section{B. pseudomallei and B. thailandensis form biofilms under different temperatures}

We assessed the ability of Burkholderia to form a biofilm under a scanning electron microscope (SEM) using B. pseudomallei JW270 strain. We depict that the biofilm formation process inBurkholderia follows the same pattern as most Gram-negative bacteria (Fig 1a). We see single cells adhere to each other (Fig 1a, step 1 ). The adherence is followed by colony aggregation (Fig 1a, step 2) and export of the biofilm components (Fig 1a, steps 3-4). Export of biofilm components progresses until most cells are covered/protected to form 
a mature biofilm (Fig 1a, step 5). Cells are dispersed from a matured biofilm to continue the cycle (Fig 1a, step 6). A visual and microscopic observation shows that all four strains used for the composition study: $B$. pseudomallei strains (Bp1026b $\Delta a \sigma \delta, \mathrm{Bp} 82$, and JW270) and B. thailandensis E264 are all able to form both an adherent biofilm at the bottom of the plate and a pellicle; a biofilm formed at the air-liquid interface (Fig 1b). We observed that pellicle morphologies differed between strains. Bp82 and JW270 present wrinkled and cloudy pellicles while 1026b $\Delta a \sigma \delta$ and E264 have a thin, smooth layer (Fig. 1b). Fig 1c shows an image of a processed JW270 pellicle. There was no difference in the SEM images between all pellicles.

B. pseudomallei is not fastidious and can grow under diverse environmental conditions [41], such as soil and rice paddy field water at temperatures between $21^{\circ} \mathrm{C}$ and $37^{\circ} \mathrm{C}[42,43]$. B. pseudomallei in the lab is commonly grown at $37^{\circ} \mathrm{C}$, a temperature that corresponds to human body temperature [44]. To compare biofilm capabilities under varying temperatures, B. pseudomallei was grown statically for 72 hours either at room temperature $\left(22^{\circ} \mathrm{C}\right)$ to represent rice paddy fields or at $37^{\circ} \mathrm{C}$ in an incubator to represent human host temperature. Fig. 1d shows that at the end of the experiment, there is no significant difference between the same strains grown at different temperatures (Student's t-test, $\mathrm{P}>0.05$ ). However, we observed that in earlier time points, cells grown at RT lagged behind $37^{\circ} \mathrm{C}$ cells but ultimately forms the same amount of biofilm by 72 hours. For comparison between groups at the end of the experiment (e.g. 1026b $\Delta a \sigma \delta$ vs. $\mathrm{Bp} 82$ at $37^{\circ} \mathrm{C}$ ), student t-tests show that there was no significant difference between biofilms formed between all strains (Fig 1e, $\mathrm{P}>0.05$ ). We also observed that cultures grown at both temperatures formed surface adherent biofilms, but cultures grown at $37^{\circ} \mathrm{C}$ are capable of forming both surface adherent biofilms and pellicles.

Biofilms formed by each Burkholderia strain is made up of eDNA, protein and polysaccharides and all components are exported by live cells.

From Fig. 1d, at the end of 72 hours, there was no significant difference between biofilms formed by cells at RT or $37^{\circ} \mathrm{C}$ hence all experiments were carried out at $37^{\circ} \mathrm{C}$. We determined the constituents of biofilms formed by all four strains using fluorescent microscopy. In Fig. 2a, we observed that all four strains exported varying amounts of eDNA, protein, and polysaccharides contents to support its biofilm structure. Closer magnifications are inserted to show molecular distribution around cell aggregates.

Previous publications have shown that in some Gram-negative organisms, eDNA is generated through cell lysis [45]. However, as indicated in Fig. 2b, live/dead images of B. pseudomallei and B. thailandensis indicate that at 48 hours, a time point by which a mature biofilm has been formed, the cells within the biofilm are predominantly viable.

\section{Biofilm components significantly differ between strains and growth mode.}

Using a previously established biofilm extraction protocol [46], we quantified the concentration of each biofilm component and compared it to the supernatant of planktonic grown bacteria. Microscopic analysis in Fig. 2 showed that different strains exported varying quantities of protein/eDNA/polysaccharides. In Fig. 3 , we used BCA (protein), phenol-sulfuric acid (glucose/polysaccharide) and propidium iodide florescence (eDNA) to quantify the concentration of biofilm grown constituents compared to a planktonic grown culture. We observed that the amount of molecules exported was determined by growth method. Between all four strains, there was a significant difference in protein, eDNA or polysaccharide content if the cells were grown with agitation (planktonic) or statically (biofilm) (Supplemental data; Table S1-3). There is no significant difference in protein concentration between 1026b $\Delta a \sigma \delta$, Bp82 and E264, but all three significantly differed from JW270 (Supplemental data; Table S1-3). It was observed that JW270 and E264 biofilms are dominantly made up of eDNA unlike 1026b $\Delta a \sigma \delta$ and Bp82 biofilms which showed higher polysaccharide and protein component. This finding was notable because 1026b $\Delta a \sigma \delta$ and Bp82 produce CPS I, but JW270 and E264 do not $[40,47]$. The results suggest that the inability of B. pseudomallei and $B$. thailandensis strains to produce CPS I for biofilm formation may be compensated by exporting more eDNA for biofilm biogenesis.

Enzymatic treatments significantly reduce specific biofilm components 
The use of enzymes- especially DNase and proteinase K- for biofilm dispersal or eradication has become quite popular [25, 48]. However, enzymes do not completely eradicate mature biofilms and have been proposed for adjuvant therapy, degradation accessible cell surface proteins and as surface coatings to prevent adhesion which is the first step of biofilm formation [49-51]. Fig. 4 confirms thatBurkholderia biofilms are sensitive to all enzymatic treatments by a 30-75\% reduction in biomass. In Fig. 4, DNase treatment is shown to be the most effective dispersal method for the B. pseudomalleistrains while proteinase $\mathrm{K} /$ glucosidase is more effective towardsB. thailandensis E264 dispersal.

\section{Morphology and composition of a Burkholderia pellicle}

B. thailandensis E264 and B. pseudomallei strains form two different types of biofilms: an adherent biofilm and a liquid-air interface biofilm (pellicle). The molecular composition of each pellicle (Fig 5a-c), mirrored the composition of the adherent biofilm (Figs 2a, 3a-c). The pellicles shows high concentrations of protein and polysaccharide and less eDNA present in pellicles of 1026b $\Delta a \sigma \delta$ and Bp82. JW270 and E264 showed higher eDNA.

\section{Comparison between wild type 1026b, DD503 and JW270}

From Figs 3 and 5, we observe that 1026b $\Delta a \sigma \delta$ and Bp82 bear the same biofilm composition while JW270 and E264 are similar despite the fact that JW270 was generated from the DD503 (Fig S1), a derivative of 1026b in which the genes encoding amrAB-oprA antibiotic efflux pump has been deleted [39]. To confirm that the mutation used to generate JW270 may be responsible for its different biofilm composition, we repeated the assays for protein, eDNA and glucose concentration using the wild type 1026b, DD503 and JW270.

1026b and its direct derivative DD503 have the similar protein concentration (Fig 6a, p =0.006), and eDNA florescence (Fig 6c, p = 0.03) at 72 hours but DD503 shows an increased polysaccharide concentration throughout the experiment time span (Fig 6b). However, once the $w c b$ operon is deleted in DD503 to generate JW270, the polysaccharide and protein concentrations drastically decreases but shows an inverse increase in eDNA. There is a significant difference between the concentrations of all biofilm components when DD503 and JW270 are compared $(\mathrm{p}=0.01-0.04)$. This data implies that the deletion of the $w c b$ cluster may be responsible for the low biofilm polysaccharide and protein concentrations and the overcompensation of eDNA export in JW270 to maintain a stable biofilm. To quickly confirm our hypothesis, we performed an ELISA test using JW270 as test sample, and 1026b $\Delta a \sigma \delta$ and Bp82 as positive controls. B. thailandensis E264 which lacks the CPS cluster was used as negative control. The ELISA test was performed using an anti-CPS primary antibody, 4B11 [52], and a goat anti-mouse alkaline phosphatase secondary antibody. The results shows reactivity between the 4B11 antibody and 1026b $\Delta a \sigma \delta$ and Bp82 but not towards JW270 or B. thailandensis E264 (Fig. S2). Taken together, the results demonstrate an inverse relationship between eDNA and CPS I inBurkholderia biofilms.

\section{Discussion}

Burkholderia is a genus of proteobacteria which harbors pathogenic and non-pathogenic members. B. pseudomallei is a gram-negative, aerobic, highly pathogenic rod-shaped bacterium. It is the causative agent for melioidosis, an infectious disease with high morbidity and mortality rates in endemic regions [53]. It is a CDC federal select agent for which there are no current vaccines available for human treatment. Molecular research on Burkholderia has focused on vaccine production mainly because of its likely use in bioterrorism but also because it exhibits intricate resistance to multiple groups of antibiotics, especially while growing in biofilms [54]. Because of the pathogenicity of B. pseudomallei, a BSL3 lab is required to work with the bacteria hence manipulations have been made to generate B. pseudomallei strains $1026 \mathrm{~b} \Delta a \sigma \delta$, Bp 82 , JW270 which are all non-pathogenic BSL2 strains. On the other hand,B. thailandensis is a non-pathogenic strain which rarely causes disease in humans $[35,55]$. Most Burkholderia biofilm studies report on biofilm using BSL2 strains. The purpose of this study was to determine if the genetic manipulations made to the pathogenic 1026b strains affected biofilm structure, formation or constituents. 
Gram-negative bacteria can form surface adherent biofilms or a biofilm formed at the air-liquid interface which is called a pellicle [1]. The biofilm formation process is activated in response to various signals such as quorum sensing [56, 57], nutrient availability [58], stress [59], and surface material as reviewed in Maganaet al , 2018 [60]. Research has shown that B. pseudomallei and B. thailandensis are capable of producing biofilms $[10,11,13,17,18,21,61,62]$ and are known to export large amounts of eDNA [25, 63]. Another biofilm characteristic is the ability to persist after treatment which causes disease relapse [54,64] - a feature widely attributed to a cohort of biofilm cells called persisters. Biofilm is involved in the antibiotic resistance of bacterial disease, relapse, and persistent cells $[65,66]$. eDNA exportation has been observed in both Grampositive and Gram-negative bacteria and has now been associated with biofilm facilitation and composition $[23,67]$.

Much like Salmonella [68], Burkholderia is capable of producing either a surface adherent biofilm or a pellicle (Fig 1a-c). This phenomenon was also demonstrated in a previous Burkholderiastudy which showed both pellicle and adherent biofilm [23]. The conditions and reasons for the change from surface adherent to pellicle biofilm remains unknown in Burkholderia. Mangalea et al . [8] reviewed that Burkholderia pellicles are typically present in the environment and surface adherent biofilms more consistent with rice paddies. This is quite similar to conditions observed in this study, $37^{\circ} \mathrm{C}$ representing the higher environmental temperature and $37^{\circ} \mathrm{C}$ a representative temperature for the cooler rice paddies. This suggests that temperature amongst other environmental conditions indicative of the two different environments may play a role in determining the type of biofilm formed. In Salmonella, curli is responsible for the switch [68] whereas, in C. crescentus, biofilm is initially formed as a monolayer of cells that subsequently develop into a three-dimensional structure and as the biofilm matures, it becomes more cohesive and less adherent [69]. Previous studies have confirmed that some pellicles of some organisms are composed of eDNA with close cell contact [23], sucrose, and proteins [70].

This study characterized the major biofilm components of B. pseudomallei 1026b, four isogenic 1026b mutants and B. thailandensis E264. Since B. pseudomallei is typically found in the soils with relatively lower temperatures than a mammalian host, we grew all strains at temperatures that reflect each environment. Fig. 1d shows that there were no temperature-related differences in biofilm formation between the strains grown at $\mathrm{RT}$ and $37^{\circ} \mathrm{C}$, so all remaining experiments were performed at $37^{\circ} \mathrm{C}$. Interestingly, the amount of biofilm formed by all the B. pseudomallei and B. thailandensisstrains at 72 hours showed no significant difference (Fig. 1e).

Fluorescent microscopy and molecular assays (Fig. 2a and 3) show that the biofilm composition of B. thailandensis is significantly composed of proteins and eDNA and lower levels of polysaccharide.B. pseudomallei 1026b $\Delta a \sigma \delta$ and Bp82 consists mainly of polysaccharides with lower protein and eDNA levels, respectively. However, JW270 appears to have consistently low protein and polysaccharide concentrations but relatively large amounts of eDNA. JW270 is a CPS I mutant [40] and is unlikely to produce the same amount of polysaccharides as 1026b $\Delta a \sigma \delta$ or Bp82. We speculate that in order to compensate for the loss of polysaccharide, there is an increased export of eDNA to serve as a skeletal biofilm structure. To confirm our speculations, we compared the concentration of the biofilm constituents of DD503, the parental strain of JW270 which lacksamrAB-oprA, a multidrug efflux system (Fig. S1). The deletion of the AmrAB-oprA efflux pump alone did not affect concentrations of biofilm protein or eDNA, but significantly increased the glucose concentration (Fig 6). JW270 was generated by deleting the wcbcluster responsible for CPS I polysaccharide in DD503 [40]. Deletion of both the AmrAB-oprA efflux pump and the $w c b$ operon led to the significant decrease in both biofilm protein and polysaccharide, but an inverse increase in the amount of eDNA exported and found in a biofilm (Fig. 6).

The differences observed in the molecular composition were not attributed to the extraction method or cell lysis during extraction. A plate count was performed before and after incubation with TE buffer to evaluate cell lysis and the number of cell count obtained before and after extraction remained constant. Florescence live/dead ratio was also carried out and Fig 2a shows that the biofilm harbor viable cells. It is also noted that as with most biofilms, these biofilms are subject to enzymatic degradation. Proteinase K/glucosidase had the 
most eradicative effect on E264 while DNase seemed to have a more profound effect on the B. pseudomallei derivatives.

In Fig. 1b-c, we observed the pellicles of Burkholderia. Morphologically, JW270 and Bp82 produced thicker pellicles, but 1026b $\Delta a \sigma \delta$ and E264 formed thinner pellicles. Microscopically in Fig 1c, the pellicles look like mesh work anchored to the walls of the wells and also shows adherent cells attached to it. In the fluorescent image in Fig. 5a, florescent dyes were used to further illustrate the composition of each strain. The data from Fig. 5a supported by the assays used in Figs. 5b and 5c, also showed that the composition of adherent biofilms (Figs 2a and 3) and pellicles (Fig. 5a-c) are quite similar.

Morphological and chemical differences exist between the biofilms of $B$. thailandensis and the B. pseudomallei derivatives 1026b $\Delta a \sigma \delta$ and Bp82, but the JW270 biofilm exhibited similarities to the E264 biofilm. We posit that the differences between B. pseudomallei JW270 and 1026b $\Delta a \sigma \delta$ or Bp82 is related to the capsule deletion necessitating the need for JW270 to export higher amounts of eDNA required for biofilm formation as observed in $B$. thailandensis E264 biofilm. This hypothesis is backed by fig 6a-c which shows that asides from glucose, the concentration of protein and eDNA remain unchanged between B. pseudomallei $1026 \mathrm{~b}$ and DD503 but once the $w c b$ operon is deleted in DD503 to generate JW270, there is a decrease in protein content but a higher export rate for eDNA. Glucose level In DD503 increased in comparison to 1026b but drops to baseline in JW270 keeping in mind that the $w c b$ operon responsible for CPS I polysaccharide. An ELISA test confirms that the difference between B. pseudomallei 1026b $\Delta a \sigma \delta / B p 82$ and B. pseudomallei JW270/ B. thailandensis E264 is the presence of a capsule. An anti-capsule antibody reacted with B. pseudomallei1026b $\Delta a \sigma \delta /$ Bp82 but not B. pseudomallei JW270/B. thailandensis E264. Biofilm assay confirmed that there was no difference in biofilm formation between all strains used.

In summary, we propose that the lack of the $w c b$ operon is the driving force behind the large amounts of eDNA exported by JW270. These differences in biofilm composition may play a role in the immune response of host organisms and also illustrate the survival of persistent cells that cause disease relapse in a host organism.

\section{Materials and Methods}

\section{Bacteria strains}

Five B. pseudomallei strains (1026b [36], DD503 [39], Bp1026b $\Delta a \sigma \delta$ [37], Bp82 [38], and JW270 [40]) and B. thailandensis E264 [35] were used for this study. Strains were either cultured on LB agar (1026b, JW270 and E264), LB agar with $100 \mu \mathrm{g} / \mathrm{ml}$ diaminopimelic acid (DAP) (1026b $\Delta a \sigma \delta$ ) or LB supplemented with $100 \mu \mathrm{g} / \mathrm{ml}$ adenine and $5 \mu \mathrm{g} / \mathrm{ml}$ thiamine (Bp82). Bacterial colonies were inoculated in $3 \mathrm{ml}$ of LB broth, with or without the corresponding supplement, and grown overnight in a $37^{\circ} \mathrm{C}$ incubator with shaking $(250$ $\mathrm{rpm}$ ) or without agitation. Bacteria were serially diluted, plated to determine bacteria count, and used for experiments. All manipulations with B. pseudomallei 1026b and DD503 were carried out in a class II microbiological safety cabinet located in a designated biosafety level 3 (BSL-3) laboratory.

\section{Biofilm formation}

Biofilm formation for B. pseudomallei strains (Bp1026b $\Delta a \sigma \delta$, Bp82, and JW270) and B. thailandensis E264 was monitored using both a scanning electron microscope (SEM) and spectrophotometric analysis of bound crystal violet (CV) in a 96 well polystyrene plate (Corning, CLS3628BC) as described by O'Toole et al [71]. For the SEM, JW270 was grown on a coverslips and each coverslip is taken out and processed at 12, 24, 34, 48 and 72 hours. To process the pellicle, the bacteria is grown in $2 \mathrm{ml}$ of broth with coverslip dropped in a 6 well plate. After 72 hours, a wide tip pipette is used to gently suction off media from the sides of the well making sure to leave the pellicle intact. Removal of the media collapses the pellicle on the coverslip. The coverslip is washed and fixed with $2.5 \%$ glutaraldehyde and $2 \%$ paraformaldehyde in $0.1 \mathrm{M}$ sodium cacodylate buffer for 1 hour. Samples were washed, post fixed with $1 \%$ osmium tetroxide, and alcohol dehydrated (30\%, $50 \%, 75 \%, 85 \%, 95 \%, 3$ changes of $100 \%$ and a single 1:1 with $100 \%$ ethanol and hexamethyldisilzane) for 10 minutes each. Sample was left to dry in 100\% HMDS for 24 hours under the hood and imaged with Carl 
Zeiss Sigma VPFE microscope.

For biofilm assay using CV, $10^{6}$ bacterial cells were added to $10 \mathrm{ml}$ of LB broth or LB broth supplemented with DAP/adenine-thiamine and 9 replicates of $200 \mu l$ per strain were cultured in six 96 well plates for 1-3 days. Three plates each were incubated either at $37^{\circ} \mathrm{C}$ or at $\mathrm{RT}$. The absorbance $\left(\mathrm{OD}_{600 \mathrm{~nm}}\right)$ of the plates were read daily and three wells of each strain were serially diluted and plated to determine bacterial counts and viability in a biofilm. Spent media in the 96-well plate were discarded and wells gently washed twice with $200 \mu \mathrm{l}$ of $1 \mathrm{x}$ PBS. One hundred microliters of $0.1 \%$ crystal violet solution was used to stain biofilm for 15mins. The biofilm was washed twice with $1 \mathrm{x}$ PBS and air-dried in a biosafety cabinet. Biofilm is extracted using $200 \mu \mathrm{l}$ of $30 \%$ acetic acid and the bound cells are quantified at an optical density of $550 \mathrm{~nm}\left(\mathrm{OD}_{550 \mathrm{~nm}}\right)$ (Molecular devices, SpectraMax M5).

\section{Immunofluorescence assay}

For CLSM imaging to confirm biofilm components or record the live/dead ratio of the B. pseudomallei and B. thailandensisbiofilms, inoculated 96 well were gently washed and molecular dyes: Film Tracer biofilm viability kit (Invitrogen L10316), DAPI stain (KPL, 71-03-00), Sypro ruby biofilm matrix stain (Invitrogen, F10318), and the Wheat germ agglutinin fluorescein conjugate (Invitrogen, W834) were used to stain wells according to each manufacturer's protocol. Wells were washed with sterile water and imaged immediately using a Nikon Eclipse 90i microscope.

\section{Planktonic and biofilm growth and extraction}

Bacterial cells $\left(10^{6}\right)$ were added to $2 \mathrm{ml}$ of LB broth and cultured in $9 \mathrm{x} 15 \mathrm{ml}$ tube (planktonic) or a 12-well plate (biofilm) for 1-3 days. The 12-well plate cultures were grown statically in a $37^{\circ} \mathrm{C}$ incubator (biofilm growth) and the $15 \mathrm{ml}$ tube cultures were grown at $37^{\circ} \mathrm{C}$ with agitation at $250 \mathrm{rpm}$ to prevent adherence (planktonic growth). At each time point, samples were taken out and a pipette used to suction spent media and the planktonic growth was centrifuged at max speed to pellet cells. One ml of sterile $1 \mathrm{x}$ PBS was added to the well and a cell scraper was used to gently detach biofilm cells. Detached biofilm cells and planktonic cells were softly pelleted at $3700 \mathrm{rpm}$ for 10 mins. Biofilm components were extracted as described in Keitheley et al. (2018) [46] with no modifications. Briefly, the pellet was resuspended in $1.5 \mathrm{ml}$ of TE buffer (10 mM Tris, $10 \mathrm{mM}$ EDTA, $2.5 \% \mathrm{NaCl}, \mathrm{pH} 8.0)$ and incubated at $200 \mathrm{rpm}$ for 4 hours at $35{ }^{\circ} \mathrm{C}$. The cells were pelleted at max speed, $4^{\circ} \mathrm{C}$ and the resulting extractant filtered and used for composition analysis. $10 \mu \mathrm{l}$ of the extractant is plated to ensure the absence of bacterial cells. A plate count was performed before and after incubation with TE buffer to determine if cell lysis occurred.

\section{Protein expression}

Pierce BCA protein assay was used to determine the biofilm protein concentration. In a 96-well plate, 25 $\mu \mathrm{l}$ of the extractant above was mixed with $200 \mu \mathrm{l}$ of $\mathrm{Cu}^{2+}$ solution according to manufacturer's protocol (Pierce, 23225). The reaction was incubated at $37^{\circ} \mathrm{C}$ for $30 \mathrm{~min}$. The absorbance was read at $\mathrm{OD}_{562 \mathrm{~nm}}$.

\section{Polysaccharide concentration}

The Phenol-sulfuric acid method, a widely used quantitative assay for glucose estimation was used to estimate the polysaccharide concentration present in a biofilm [72]. Briefly, $150 \mu \mathrm{l}$ of extractant was added to $450 \mu \mathrm{l}$ of concentrated sulfuric acid and $90 \mu \mathrm{l}$ of $5 \%$ phenol in a $13 \mathrm{~mm}$ glass tube. The tube was gently swirled to mix, incubated in a $90{ }^{\circ} \mathrm{C}$ water bath for 10 mins and cooled to RT. Two hundred microliters was pipetted in triplicates into a 96 -well plate and absorbance measured at $\mathrm{OD}_{490 \mathrm{~nm}}$. Varying concentrations of glucose $(2 / 1.75 / 1.5 / 1 / 0.5 / 0 \mathrm{mg} / \mathrm{ml})$ were used for the control and standard curve.

\section{eDNA concentration}

Using a 96-well plate, triplicates of $25 \mu$ l of extractant was added to $175 \mu$ of $0.1 \%$ propidium iodide dissolved in water. The reaction was incubated with gentle agitation in the dark, at RT for 10 mins to mix. Wells were excited at $535 \mathrm{~nm}$ and florescence read at $620 \mathrm{~nm}$. $200 \mu \mathrm{l}$ of $0.1 \%$ propidium iodide was used as blank. 


\section{Enzymatic treatment of biofilm}

Biofilms were grown in a 96-well plate as described above. Wells were either treated with $2 \mathrm{U} / \mathrm{ml}$ of DNase, $15 \mu \mathrm{g} / \mathrm{ml}$ proteinase K or $3 \mu \mathrm{g} / \mathrm{ml}$ of glucosidase (Sigma G4511-100UN) to target eDNA, protein or polysaccharide components of each biofilm. Treatments occurred at the time of inoculation. Biofilm was determined using CV as previously described.

\section{Immunofluorescence microscopy}

Bacteria pellicles were gently lifted from both sides using two sterile pipette tips or a measuring microspatula and placed on a poly-l-lysine coated slide. The pellicle is gently washed by pipetting sterile PBS over it to remove non-adherent bacteria and left to adhere for 30mins. The slide is flooded with $3 \mu \mathrm{M}$ DAPI (Invitrogen, D1306), $5 \mu \mathrm{g} / \mathrm{ml}$ wheat germ agglutinin fluorescein conjugate (WGA), (Invitrogen, W834), and $200 \mu l$ Sypro ruby biofilm matrix stain (Invitrogen, F10318) in a total volume of 500 $\mu$. The slide is incubated in the dark for 30mins, gently washed with sterile water, air-dried in the dark, and imaged as described above.

\section{Extraction, molecular determination and imaging of pellicle components}

$1 \mathrm{ml}$ of PBS was added to a $1.5 \mathrm{ml}$ tube and the pellicle is scooped with a micro-spatula, dropped into the tube, gently washed at $5000 \mathrm{rpm}$. $500 \mu \mathrm{l}$ of TE buffer is added and components are extracted and quantified as previously described.

\section{Statistical analysis}

All experiments were independently repeated three times.

Each biofilm assay experiments was conducted as independent samples of six and mean values compared within and between groups using the student's t-tests.

All biofilm extraction experiments were conducted as three independent experiments and mean values compared between groups using the student's t-tests.

Graphpad Prism 9 (GraphPad Software, LLC) was used for statistical analysis. Differences were statistically different for a $\mathrm{P}$-value $<0.05$.

\section{Data Availability}

The authors declare that the data supporting the findings of this study are available within the paper [and its supplementary information files]. Data generated will be deposited on figshare on acceptance.

\section{References}

1. Armitano, J., Mejean, V., and C. Jourlin-Castelli, Gram-negative bacteria can also form pellicles. Environ Microbiol Rep, 6 (6): p. 534-44, (2014).

2. Flemming, H.C. and Wingender, J. The biofilm matrix. Nat Rev Microbiol, 2010. 8 (9): p. 623-33.

3. Wolcott, R. and S. Dowd, The Role of Biofilms: Are We Hitting the Right Target? Plastic and Reconstructive Surgery, 127 : p. 28S-35S (2011).

4. Lewis, K., Multidrug tolerance of biofilms and persister cells. Curr Top Microbiol Immunol, 2008. 322 : p. 107-31.

5. Costerton, J.W., Stewart, P.S., and Greenberg, E.P.. Bacterial Biofilms: A Common Cause of Persistent Infections. Science,284 (5418): p. 1318-1322 (1999).

6. Vorachit, Lam K., Jayanetra .P, Costerton J. W., Electron microscopy study of the mode of growth of Pseudomonas pseudomallei in vitro and in vivo. Journal of Tropical Medicine and Hygiene, 98 (6): p. 379-391 (1995). 
7. Kamjumphol, W., Kamjumphol, W., Chareonsudjai, P., Taweechaisupapong, S., and Chareonsudjai, S. Morphological Alteration and Survival ofBurkholderia pseudomallei in Soil Microcosms. The American journal of tropical medicine and hygiene, 93 (5): p. 1058-1065 (2015).

8. Mangalea, M.R., Plumley, B.A., and Borlee, B.R., Nitrate Sensing and Metabolism Inhibit Biofilm Formation in the Opportunistic PathogenBurkholderia pseudomallei by Reducing the Intracellular Concentration of c-di-GMP. Frontiers in Microbiology, 8 (1353) (2017).

9. Long, P., et al., Melioidosis, Singapore, 2003-2014. Emerging Infectious Disease journal, 24 (1): p. 140 (2018).

10. Duangurai, T., Indrawattana N., and Pumirat P., Burkholderia pseudomallei Adaptation for Survival in Stressful Conditions. BioMed research international, 2018 : p. 3039106-3039106 (2018).

11. Inglis, T.J. and J.L. Sagripanti, Environmental factors that affect the survival and persistence of Burkholderia pseudomallei . Appl Environ Microbiol, 72 (11): p. 6865-75 (2006).

12. Aziz, A., et al., Comparative genomics confirms a rare melioidosis human-to-human transmission event and reveals incorrect phylogenomic reconstruction due to polyclonality. Microb Genom, 6 (2) (2020).

13. Wiersinga, W.J., et al., Melioidosis: insights into the pathogenicity of Burkholderia pseudomallei . Nature Reviews Microbiology, 4 (4): p. 272-282 (2006).

14. Chantratita, N., et al., Antimicrobial resistance to ceftazidime involving loss of penicillin-binding protein 3 in Burkholderia pseudomallei . Proceedings of the National Academy of Sciences,108 (41): p. 17165 (2011).

15. Cheng, A.C. and B.J. Currie, Melioidosis: epidemiology, pathophysiology, and management. Clin Microbiol Rev, 18 (2): p. 383-416 (2005).

16. Perumal Samy, R., Stiles, B.G, Sethi, G., Lim, L.H.K. Melioidosis: Clinical impact and public health threat in the tropics. PLoS neglected tropical diseases, 11 (5): p. e0004738-e0004738 (2017).

17. Barsoumian, A.E., et al., Clinical infectious outcomes associated with biofilm-related bacterial infections: a retrospective chart review. BMC Infectious Diseases, 15 (1): p. 223 (2015).

18. Panomket, P., Wongsana, P., Wanram, S., Wongratanacheewin, S.Burkholderia pseudomallei biofilm plays a key role in chronic inflammation in c57bl/6 mice. Southeast Asian J Trop Med Public Health,48 (1): p. 73-82. (2017).

19. Pumirat, P., et al., Global transcriptional profiling of Burkholderia pseudomallei under salt stress reveals differential effects on the Bsa type III secretion system. BMC Microbiol,10 : p. 171. (2010).

20. Hamad, M.A., et al., Adaptation and antibiotic tolerance of anaerobic Burkholderia pseudomallei . Antimicrob Agents Chemother,55 (7): p. 3313-23 (2011).

21. Tabunhan, S., et al., Characterization of a novel two-component system response regulator involved in biofilm formation and a low-iron response of Burkholderia pseudomallei . Southeast Asian J Trop Med Public Health, 45 (5): p. 1065-79 (2014).

22. Reamtong, O., et al., Altered proteome of a Burkholderia pseudomallei mutant defective in short-chain dehydrogenase affects cell adhesion, biofilm formation and heat stress tolerance. PeerJ,8 : p. e8659 (2020).

23. Alwis, P.A., et al., Disruption of the Burkholderia pseudomallei two-component signal transduction system BbeR-BbeS leads to increased extracellular DNA secretion and altered biofilm formation. Veterinary Microbiology, 242 : p. 108603 (2020).

24. Gloag, E.S., et al., Self-organization of bacterial biofilms is facilitated by extracellular DNA. Proceedings of the National Academy of Sciences, 110 (28): p. 11541-11546 (2013). 
25. Pakkulnan, R., et al., Extracellular DNA facilitates bacterial adhesion during Burkholderia pseudomallei biofilm formation. PloS one, 14 (3): p. e0213288-e0213288. (2019).

26. Austin, C.R., et al., A Burkholderia pseudomallei colony variant necessary for gastric colonization. mBio, 6 (1). (2015).

27. Cloutier, M., Muru K., Ravicoularamina G. and Gauthier C. Polysaccharides from Burkholderia

p. 10.1128/microbiolspec.MB-0011-2014. (2015).

29. Khan, M.M., et al., Temporal proteomic profiling reveals changes that support Burkholderia biofilms. Pathogens and disease, 77 (2): p. 005. (2019).

30. Cherny, K.E. and K. Sauer,. Untethering and Degradation of the Polysaccharide Matrix Are Essential Steps in the Dispersion Response of Pseudomonas aeruginosa Biofilms. J Bacteriol, 202 (3). (2020).

31. Li, Y., et al., BdlA, DipA and induced dispersion contribute to acute virulence and chronic persistence of Pseudomonas aeruginosa. PLoS Pathog, 10 (6): p. e1004168. (2014).

32. Cherny, K.E. and K. Sauer,. Pseudomonas aeruginosa Requires the DNA-Specific Endonuclease EndA To Degrade Extracellular Genomic DNA To Disperse from the Biofilm. Journal of Bacteriology, 201 (18): p. e00059-19. (2019).

33. Nait Chabane, Y., et al., Characterisation of pellicles formed by Acinetobacter baumannii at the airliquid interface. PloS one,.9 (10): p. e111660-e111660. (2014).

34. Eladawy, M., et al., Effects of Lysozyme, Proteinase K, and Cephalosporins on Biofilm Formation by Clinical Isolates of Pseudomonas aeruginosa. Interdiscip Perspect Infect Dis, 2020 : p. 6156720 (2020).

35. Brett, P.J., D. DeShazer, and D.E. Woods, Burkholderia thailandensis sp. nov., a Burkholderia pseudomallei -like species. Int J Syst Bacteriol, 48 Pt 1 : p. 317-20. (1998).

36. DeShazer, D., Brett P.J, Carlyon R., Woods D.E,. Mutagenesis ofBurkholderia pseudomallei with Tn5-OT182: isolation of motility mutants and molecular characterization of the flagellin structural gene. J Bacteriol, 179 (7): p. 2116-25. (1997).

37. Norris, M.H., et al., The Burkholderia pseudomallei Deltaasd mutant exhibits attenuated intracellular infectivity and imparts protection against acute inhalation melioidosis in mice. Infect Immun,79 (10): p. 4010-8 (2011)

38. Propst, K.L., et al., A Burkholderia pseudomallei deltapurM mutant is avirulent in immunocompetent and immunodeficient animals: candidate strain for exclusion from select-agent lists. Infection and immunity, 78 (7): p. 3136-3143 (2010).

39. Moore, R.A., DeShazer D., Reckseidler, S., Weissman, A., Woods, D.E.. Efflux-mediated aminoglycoside and macrolide resistance inBurkholderia pseudomallei. Antimicrobial agents and chemotherapy,43 (3): p. 465-470. (1999).

40. Warawa, J.M., et al., Role for the Burkholderia pseudomalleicapsular polysaccharide encoded by the wcb operon in acute disseminated melioidosis. Infect Immun, 77 (12): p. 5252-61 (2009).

41. Peacock, S.J., et al., Comparison of Ashdown's medium, Burkholderia cepacia medium, and Burkholderia pseudomallei selective agar for clinical isolation of Burkholderia pseudomallei. J Clin Microbiol, 43 (10): p. 5359-61. (2005).

42. Ong, C.E.L., et al., Presence of Burkholderia pseudomallei in Soil and Paddy Rice Water in a Rice Field in Northeast Thailand, but Not in Air and Rainwater. Am J Trop Med Hyg, 97 (6): p. 1702-1705. (2017).

43. Bheemanahalli, R., et al., Temperature thresholds for spikelet sterility and associated warming impacts for sub-tropical rice. Agricultural and Forest Meteorology, 221 : p. 122-130 (2016). 
44. Mackowiak, P.A., Wasserman, S.S., and Levine, M.M., A critical appraisal of 98.6 degrees F, the upper limit of the normal body temperature, and other legacies of Carl Reinhold August Wunderlich. Jama, 268 (12): p. 1578-80 (1992).

45. Montanaro, L., et al., Extracellular DNA in biofilms. Int J Artif Organs, 34 (9): p. 824-31 (2011).

46. Keithley, S.E. and Kirisits, M.J. An improved protocol for extracting extracellular polymeric substances from granular filter media. Water Research, 129 : p. 419-427. (2018).

47. Kim, H.S., et al., Bacterial genome adaptation to niches: divergence of the potential virulence genes in three Burkholderia species of different survival strategies. BMC Genomics, 6 : p. 174 (2005).

48. Tetz, G.V., Artemenko, N.K., and Tetz, V.V., Effect of DNase and antibiotics on biofilm characteristics. Antimicrobial agents and chemotherapy, 53 (3): p. 1204-1209 (2009).

49. Wolfmeier, H., Pletzer, D., Mansour, S. C., and Hancock R.E.W. New Perspectives in Biofilm Eradication. ACS Infect Dis, 4 (2): p. 93-106. (2018).

50. Swartjes, J.J.T.M., et al., A Functional DNase I Coating to Prevent Adhesion of Bacteria and the Formation of Biofilm. Advanced Functional Materials, 23 (22): p. 2843-2849 (2013).

51. Kaplan, J.B., et al., Enzymatic detachment of Staphylococcus epidermidis biofilms. Antimicrob Agents Chemother, 48 (7): p. 2633-6 (2004).

52. Anuntagool, N., Naigowit, P., Petkanchanapong, V., Aramsri, P. Monoclonal antibody-based rapid identification of Burkholderia pseudomallei in blood culture fluid from patients with community-acquired septicaemia. Journal of medical microbiology,.49 : p. 1075-8 (2001).

53. Wiersinga, W.J., et al., Melioidosis. Nature reviews. Disease primers, 4 : p. 17107-17107 (2018).

54. Anutrakunchai, C., et al., Impact of nutritional stress on drug susceptibility and biofilm structures of Burkholderia pseudomallei and Burkholderia thailandensis grown in static and microfluidic systems. PloS one, 13 (3): p. e0194946-e0194946 (2018).

55. Smith, M.D., Angus, B. J., Wuthiekanun, V., White, N.J., Arabinose assimilation defines a nonvirulent biotype of Burkholderia pseudomallei . Infect Immun, 65 (10): p. 4319-21 (1997).

56. Eberl, L., Quorum sensing in the genus Burkholderia . Int J Med Microbiol, 296 (2-3): p. 103-10 (2006).

57. Rutherford, S.T. and Bassler, B.L., Bacterial quorum sensing: its role in virulence and possibilities for its control. Cold Spring Harbor perspectives in medicine, 2 (11): p. a012427 (2012).

58. Leiman, S.A., et al., D-amino acids indirectly inhibit biofilm formation in Bacillus subtilis by interfering with protein synthesis. J Bacteriol, 195 (23): p. 5391-5 (2013).

59. Tseng, B.S., et al., Quorum Sensing Influences Burkholderia thailandensis Biofilm Development and Matrix Production. Journal of Bacteriology, 198 (19): p. 2643. (2016).

60. Magana, M., et al., Options and Limitations in Clinical Investigation of Bacterial Biofilms. Clinical microbiology reviews,31 (3): p. e00084-16 (2018).

61. Limmathurotsakul, D., et al., Role of Burkholderia pseudomallei biofilm formation and lipopolysaccharide in relapse of melioidosis. Clin Microbiol Infect, 20 (11): p. O854-6 (2014).

62. Sawasdidoln, C., et al., Growing Burkholderia pseudomallei in biofilm stimulating conditions significantly induces antimicrobial resistance. PLoS One, 5 (2): p. e9196 (2010).

63. DeShazer, D., et al., Bacteriophage-associated genes responsible for the widely divergent phenotypes of variants of Burkholderia pseudomallei strain MSHR5848. Journal of medical microbiology,68 (2): p. 263-278. (2019). 
64. Currie, B.J., Fisher D. A., Anstey N.M., Jacups S.P., Melioidosis: acute and chronic disease, relapse and re-activation. Trans R Soc Trop Med Hyg, 94 (3): p. 301-4 (2000).

65. Keren, I., Kaldalu, N., Spoering, A., Wang, Y., Lewis, K., Persister cells and tolerance to antimicrobials. FEMS Microbiol Lett,230 (1): p. 13-8 (2004).

66. Chambless, J.D., Hunt ,S.M., and Stewart, P.S., A three-dimensional computer model of four hypothetical mechanisms protecting biofilms from antimicrobials. Appl Environ Microbiol,. 72 (3): p. 2005-13. (2006)

67. Gloag, E.S., et al., Self-organization of bacterial biofilms is facilitated by extracellular DNA. Proceedings of the National Academy of Sciences, 110 (28): p. 11541 (2013).

68. Paytubi, S., Cansado, C., Madrid, C., and Balsalobre, C., Nutrient Composition Promotes Switching between Pellicle and Bottom Biofilm in Salmonella. Frontiers in microbiology,. 8 : p. 2160-2160 (2017)

69. Fiebig, A., Role of Caulobacter Cell Surface Structures in Colonization of the Air-Liquid Interface. Journal of Bacteriology,.201 (18): p. e00064-19 (2019).

70. Koo, H., M.L. Falsetta, and M.I. Klein, The exopolysaccharide matrix: a virulence determinant of cariogenic biofilm. Journal of dental research, 92 (12): p. 1065-1073 (2013).

71. Moore, R.A., et al., Efflux-mediated aminoglycoside and macrolide resistance in Burkholderia pseudomallei . Antimicrob Agents Chemother, 43 (3): p. 465-70 (1999).

72. O'Toole, G.A., Microtiter Dish Biofilm Formation Assay. JoVE, (47): p. e2437 (2011).

73. DuBois, M., et al., Colorimetric Method for Determination of Sugars and Related Substances. Analytical Chemistry, 28 (3): p. 350-356 (1956).

\section{Author Information}

\section{Contributions}

D.D and U.O. conceived the experimental idea and wrote the manuscript. U.O. verified the protocol, planned and performed the experiments and data analysis. S.M. performed the experiments in the BLS3. D.D. supervised the findings of this work.

\section{Corresponding author}

Correspondence to David DeShazer.

\section{Funding Information.}

This research was performed while the author - UO- held an NRC Research Associateship award at the DeShazer Lab at the United States Army Medical Research Institute of Infectious Diseases (USAMRIID), Frederick, Maryland, USA.

This work was supported by DTRA/JSTO-CBD under Grant CB10207 (to D.D.). Opinions, interpretations, conclusions, and recommendations are those of the authors and are not necessarily endorsed by the U.S. Army.

\section{Competing Interests statement}

The authors declare no competing interests.

\section{Figure Legends}

Figure 1. Effect of temperature on biofilm formation in different Burkholderia strains (B. pseudomallei 1026b $\Delta a \sigma \delta$, Bp82, JW270 and B. thailandensis E264). a. Biofilm formation life cycle in B. pseudomallei JW270 b. Pellicle images of Burkholderia strains. c. Image of a B. pseudomallei JW270 pellicle post processing vs micrograph image of the pellicle. Red lines lead to an SEM image which shows that the pellicles are made up 
the extracellular materials (eDNA, proteins and polysaccharides) and bacterial cells. There was no difference in pellicle morphology on the SEM. Bar $2 \mu \mathrm{M}$. d. Crystal violet quantification of Burkholderiabiofilms under different temperatures shows that there is no significant difference in biofilm formation at the end of the experiment -72 hours $(\mathrm{P}>0.05)$. e. Biofilm formation of all 4 strains at $37^{\circ} \mathrm{C}$ after 72 hours shows that there is no significant difference between the biofilms formed by B. pseudomallei strains or by B. thailandensis , ( $\mathrm{P}>0.05$ for each comparison).

Figure 2. Microscopic images of Burkholderia biofilm. a. 10x Microscopic images of 72 hours Burkholderia biofilms which shows the biofilms are composed of eDNA (Dapi), proteins (Sypro ruby) and polysaccharides (WGA) White bar - 200um. Inserts are 100x Microscopic images showing the cells within a biofilm. Red bar $-100 \mu \mathrm{m}$. b. Live/dead image of cells 0-48 hours showing that the cells are viable throughout the biofilm process (Bar- 10um).

Figure 3 shows that there is a significant difference between the amounts exported when comparing between growth modes ( $\mathrm{p} ;$ 0.05). As expected, biofilm cells export higher amount of all constituents compared to planktonic cells. In figures $3 \mathrm{a}-3 \mathrm{c}$, we observe that $1026 \mathrm{~b} \Delta a \sigma \delta$ and $\mathrm{Bp} 82$ export high levels of (a) protein and (b) polysaccharide and low levels of (c) eDNA. JW270 biofilm on the other hand show higher levels of eDNA and minimal protein and polysaccharide export while $B$. thailandensis exports high protein and eDNA and lower polysaccharide levels when compared with B. pseudomallei 1026b $\Delta a \sigma \delta$ and Bp82.

Figure 4. Effects of enzymatic treatments on 72 hoursBurkholderia biofilms. Data shows that there is a significant difference between untreated biofilms and enzyme treated biofilm. $\quad\left(*=p ; 0.05,{ }^{* *}=p=\right.$ $\left.0.01-0.05,{ }^{* * *}=\mathrm{p}=0.01-0.007\right)$.

Figure 5. Morphology and composition of Burkholderia pellicles. a. Fluorescent images of a Burkholderia pellicles showing eDNA (blue), Polysaccharides (green), Sypro ruby (red). b. Polysaccharide (black bars) and protein (red line) compositions extracted from 72 hour pellicles. c. Quantification of eDNA extracted from a 72 hour pellicle and read using propidium iodide and a spectrophotometer. Bars represent average of three independent experiment and Error bars represent SEM.

Figure 6. Comparison between 1026b, DD503, and JW270 biofilms. Graphs a-c show concentrations of protein and glucose and eDNA levels respectively. There is no significant difference between the protein and eDNA of 1026b and DD503 at the end of the experiment, 72 hours $(\mathrm{p}>0.05)$ whereas DD503 and JW270 differed significantly at each time point except the 48 hours eDNA concentration $(\mathrm{p}<0.05)$. There is also a significant difference between the glucose concentrations for all three strains.

\section{Figures}



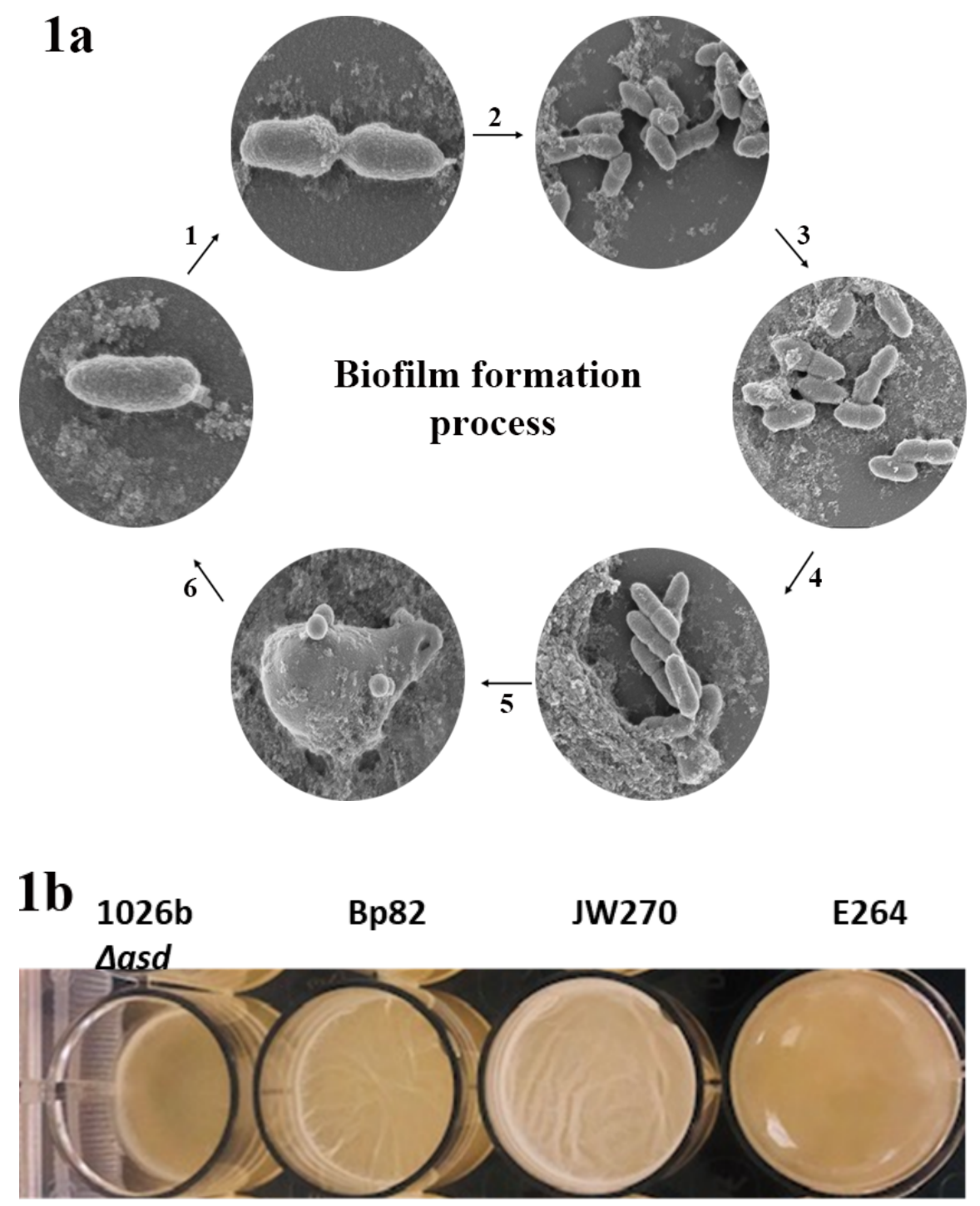


\section{$1 c$}

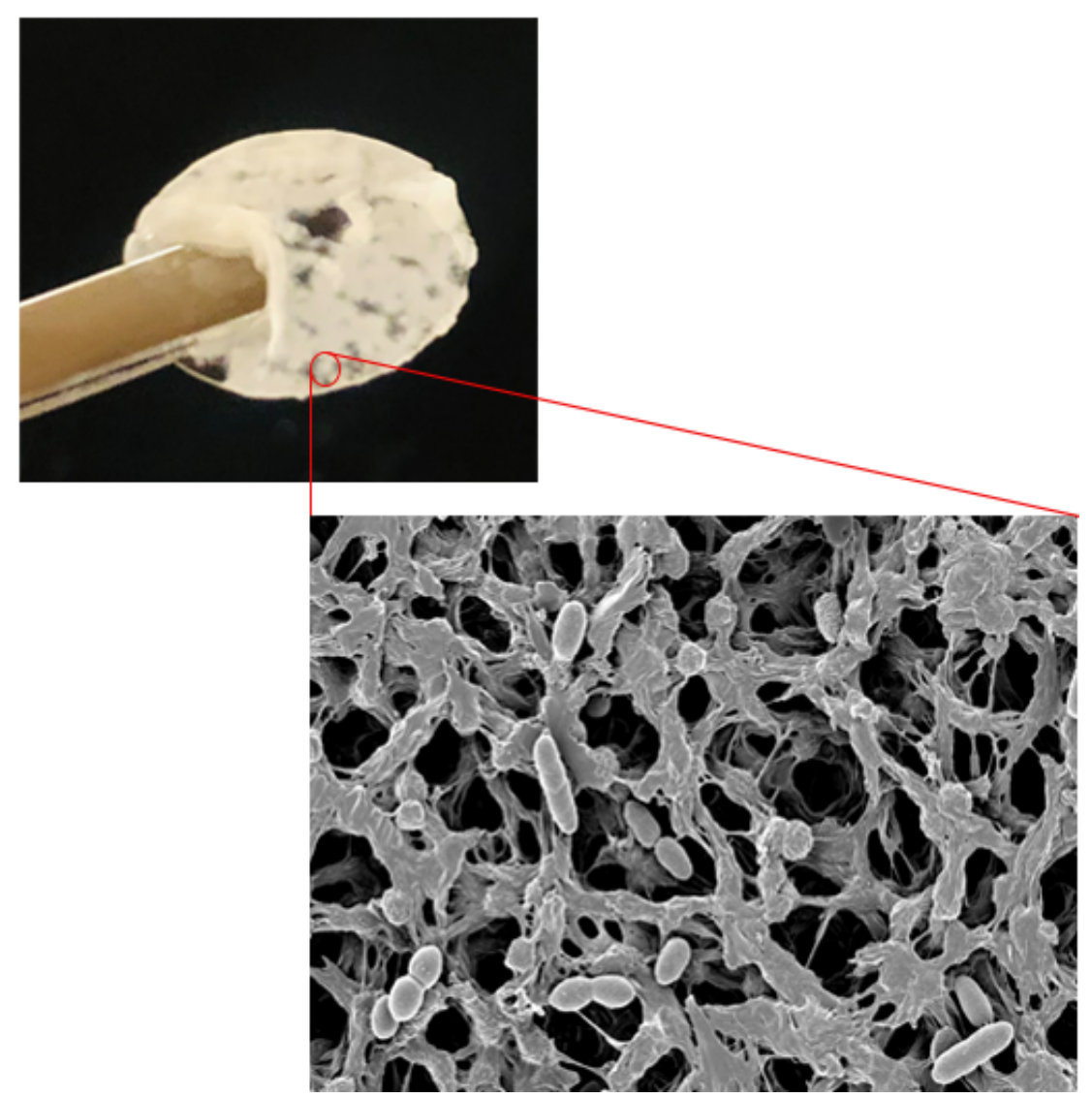

1d
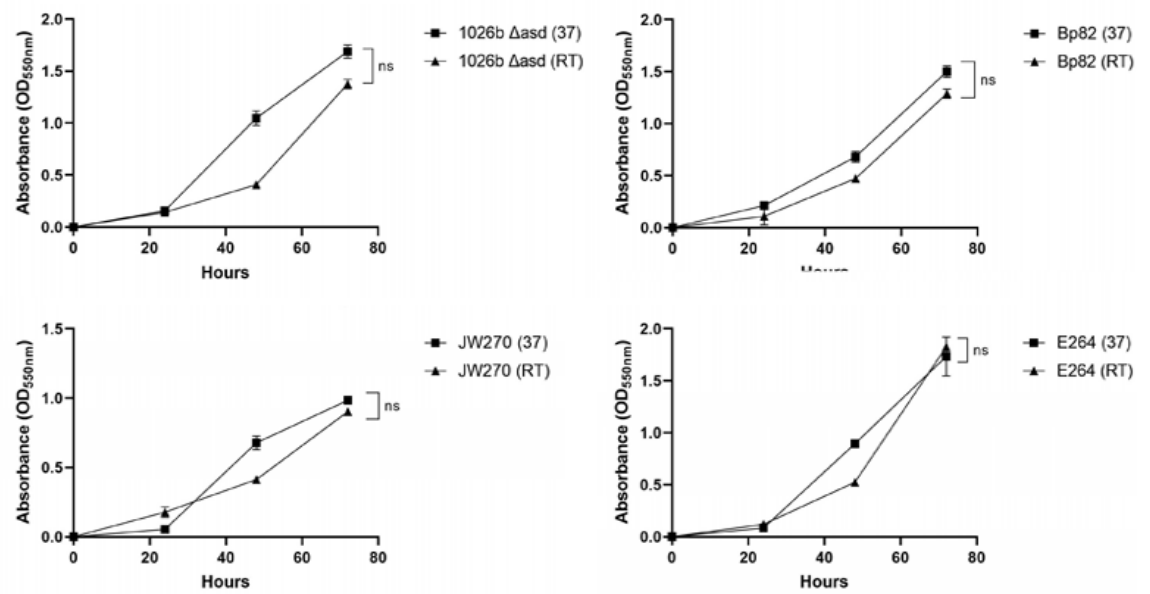

- JW270 (37)
- JW270 (RT)

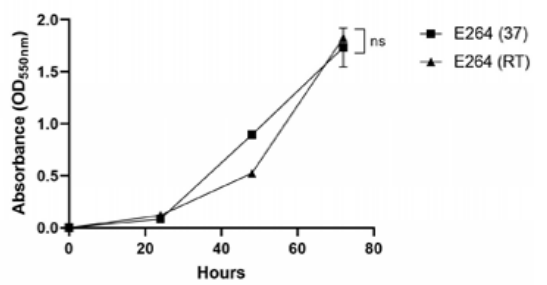


$1 \mathrm{e}$
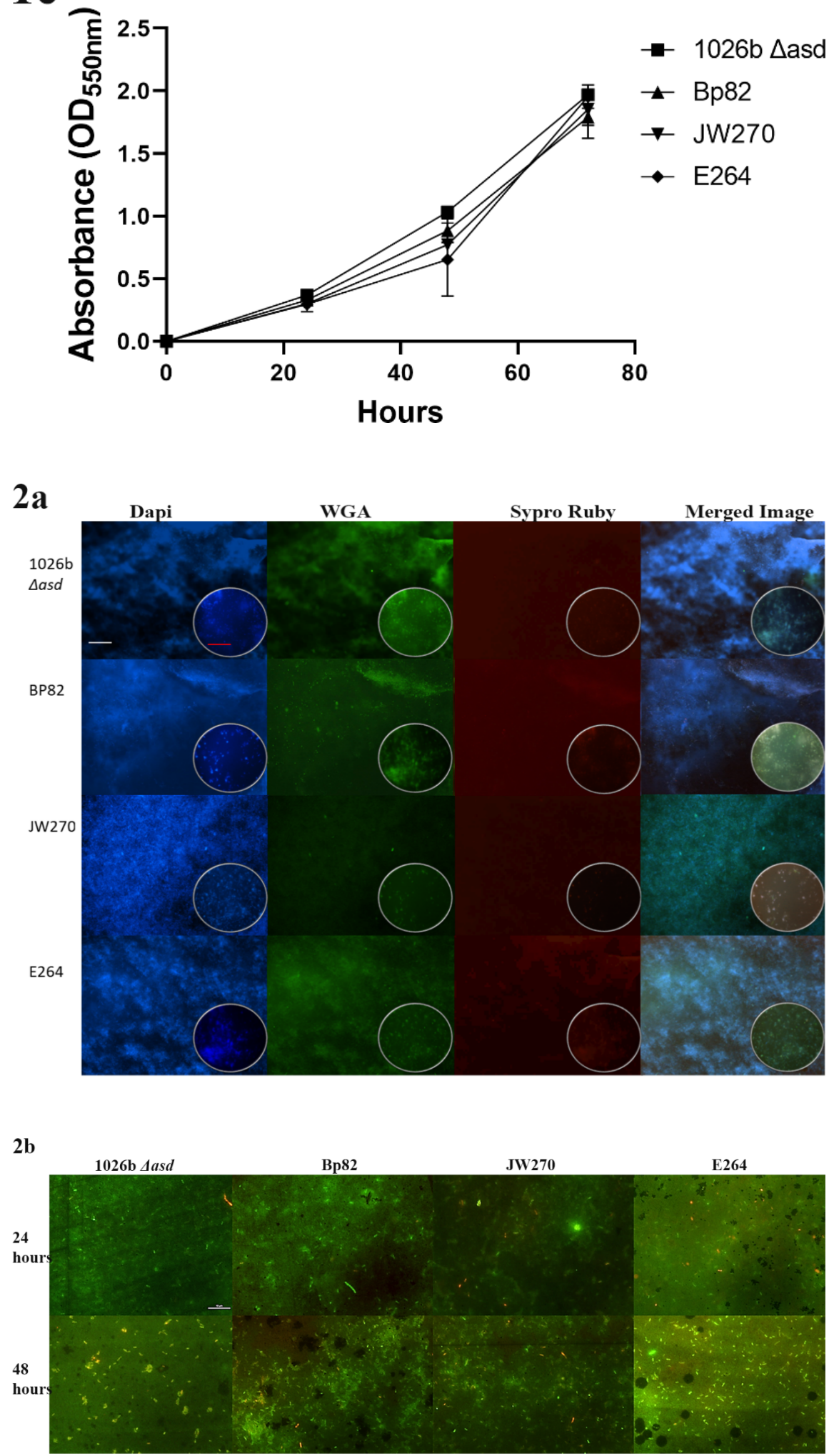
$3 a$

Proteins

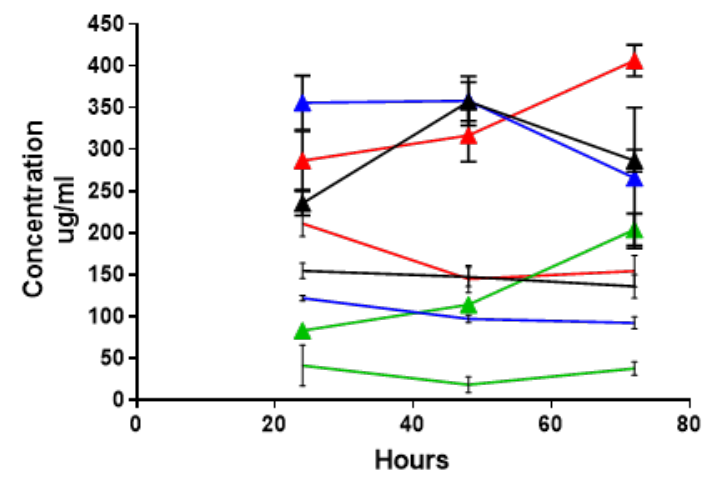

\ 1026b $\Delta$ asd (biofilm)

- 1026b $\Delta$ asd (planktonic)

Ł Bp82 (biofilm)

- Bp82 (planktonic)

+ JW270 (biofilm)

- JW270 (planktonic)

^ E264 (biofilm)

- E264 (planktonic)

$3 b$

Polysaccharides

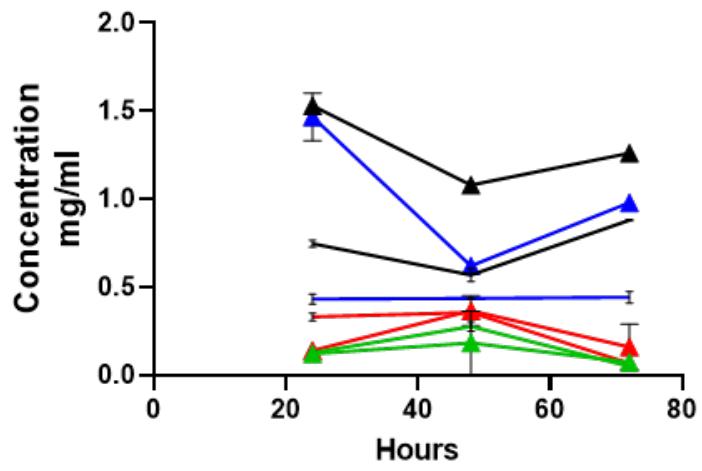

^ 1026b $\Delta$ asd (biofilm)

- 1026b $\Delta$ asd (planktonic)

+ Bp82 (biofilm)

- Bp82 (planktonic)

— JW270 (biofilm)

- JW270 (planktonic)

- E264 (biofilm)

- E264 (planktonic)

$3 c$

eDNA

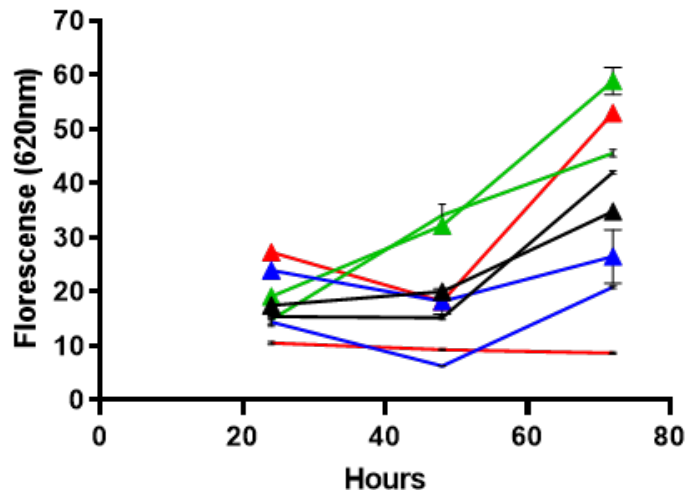

× 1026b $\Delta$ asd (biofilm)

- 1026b $\Delta$ asd (planktonic)

— Bp82 (biofilm)

- Bp82 (planktonic)

- JW270 (biofilm)

- JW270 (planktonic)

^ E264 (biofilm)

- E264 (planktonic) 
4

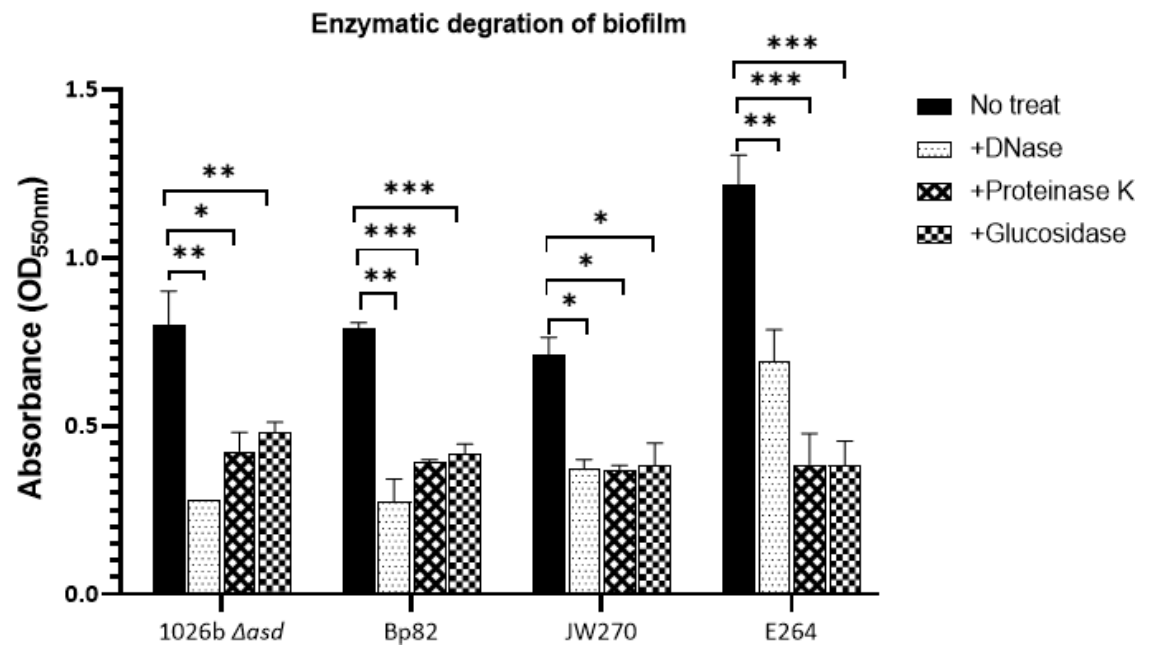

5a

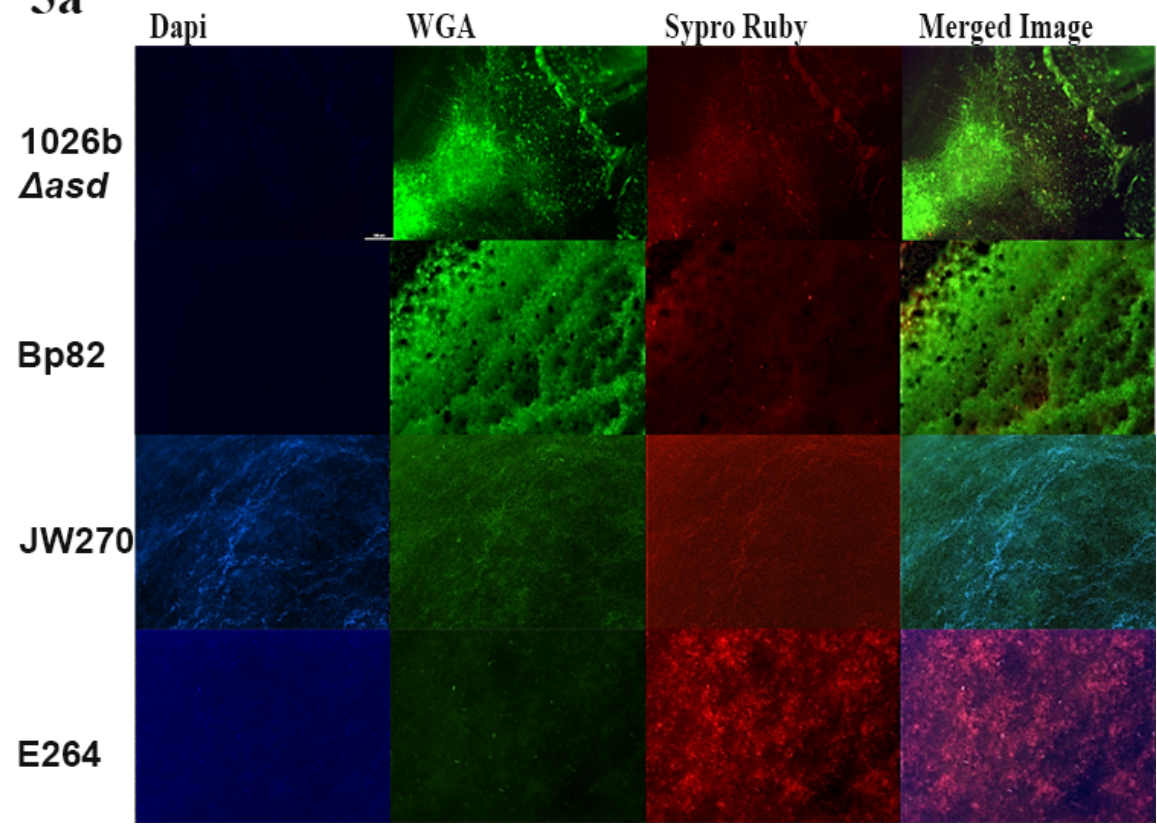




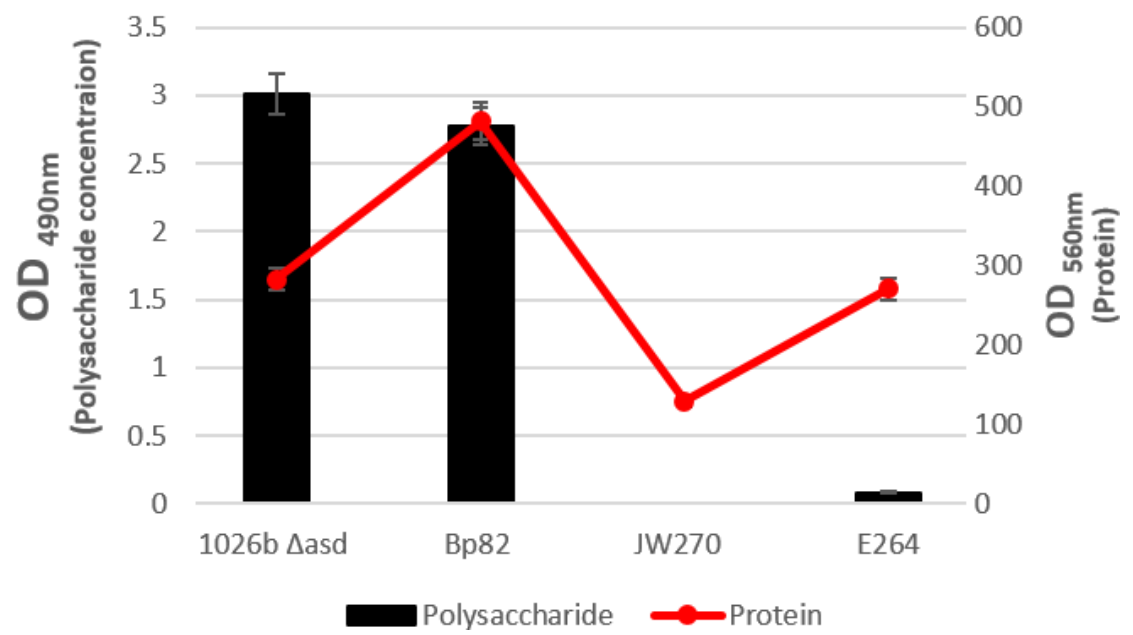

$5 c$

Pellicle eDNA composition

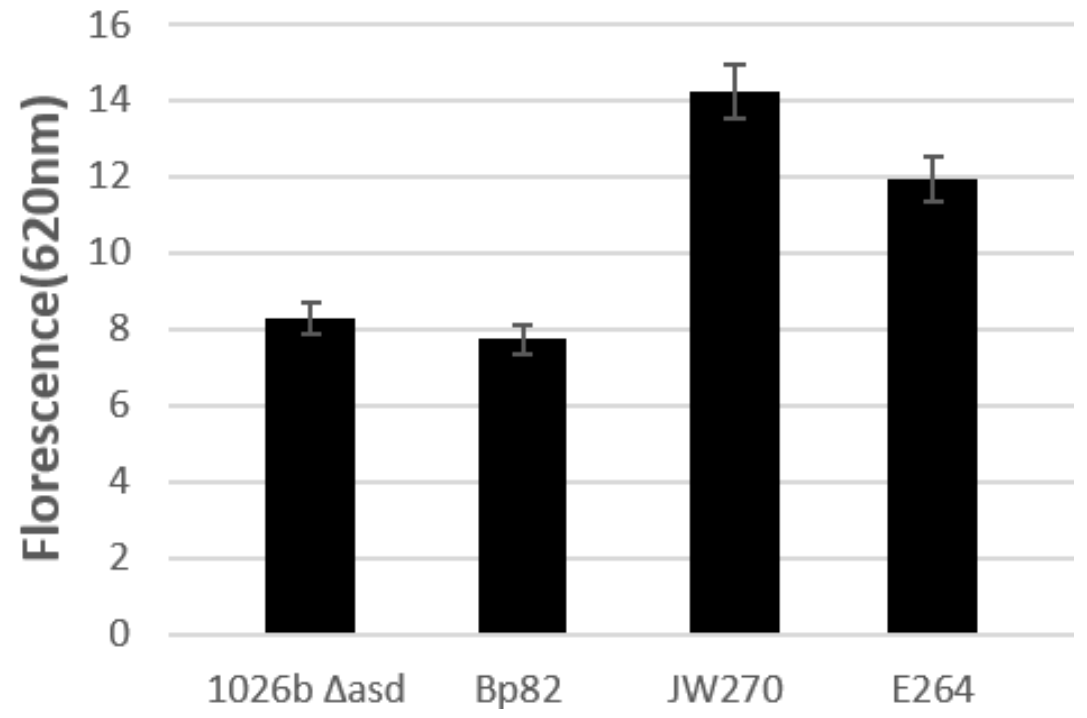


6a

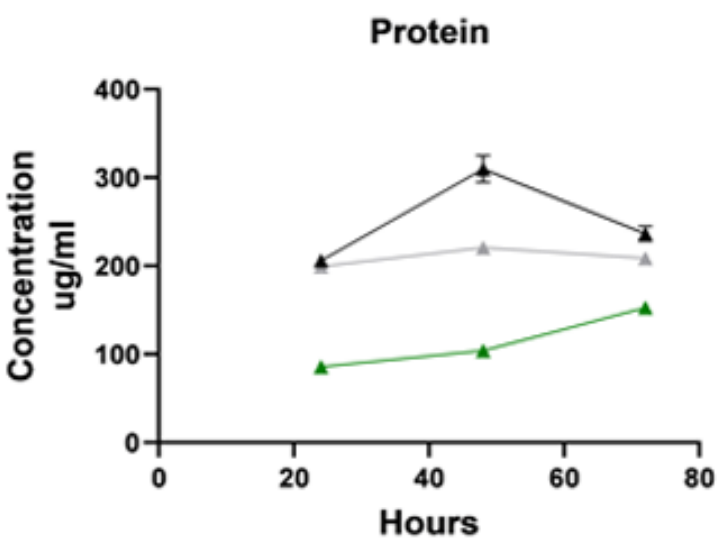

6b

\section{Polysaccharides}

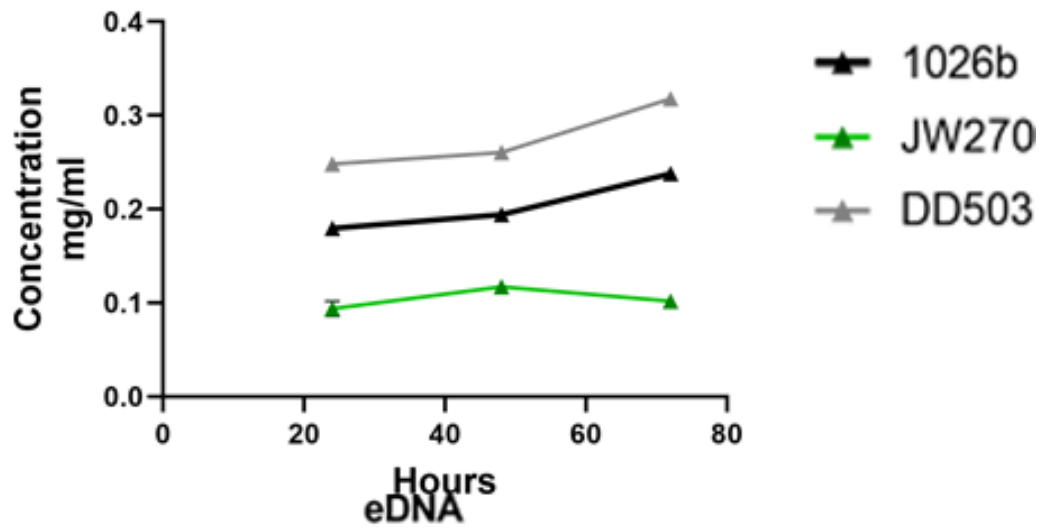

6c

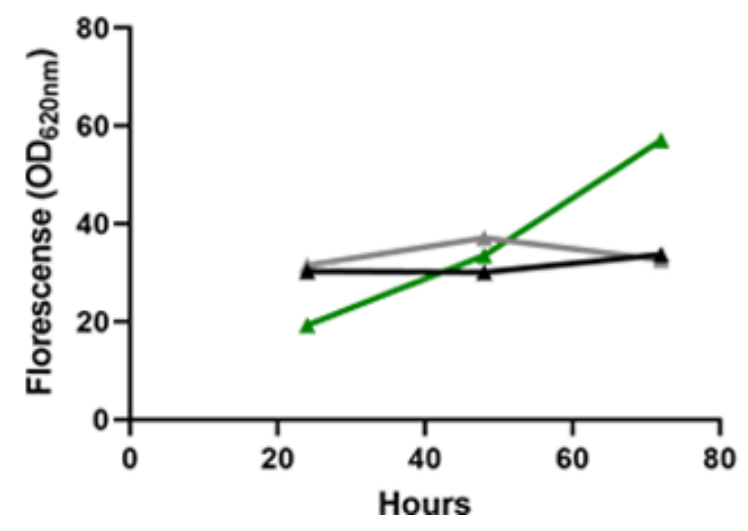

Supplemental Data 


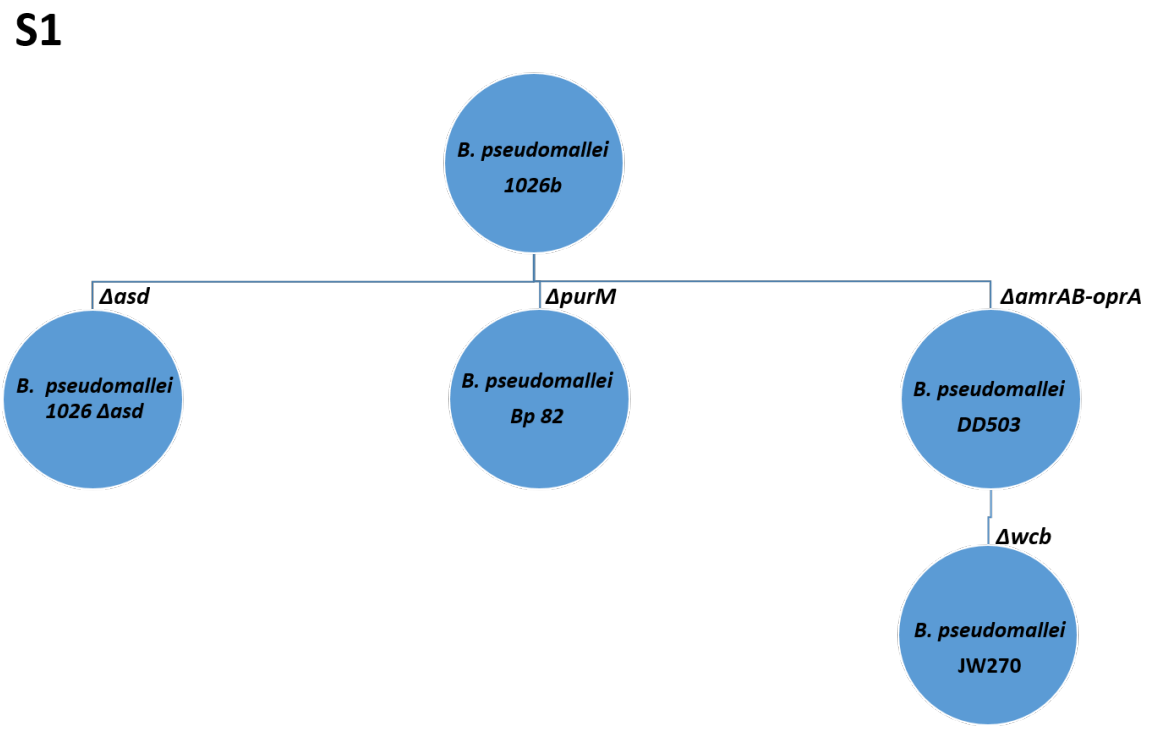

Fig S1. Hierarchy and genetic manipulations for the B. pseudomallei strains used for this study.

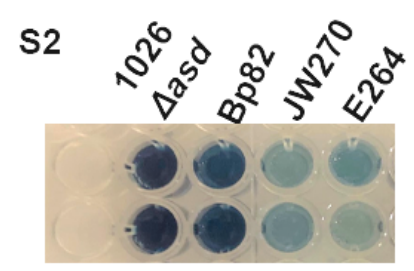

Fig S2. ELISA test to confirm reaction between an anti-CPS antibody and the strains used for this study. Table S1. Protein analysis of strains and growth procedure. 


\section{Hosted file}

image16.emf available at https://authorea.com/users/414433/articles/522470-productionand-molecular-composition-of-burkholderia-pseudomallei-and-burkholderia-thailandensisbiofilms

Table S2. Glucose analysis of strains and growth procedure.

\section{Hosted file}

image17.emf available at https://authorea.com/users/414433/articles/522470-productionand-molecular-composition-of-burkholderia-pseudomallei-and-burkholderia-thailandensisbiofilms

Table S3. eDNA analysis of strains and growth procedure.

\section{Hosted file}

image18.emf available at https://authorea.com/users/414433/articles/522470-productionand-molecular-composition-of-burkholderia-pseudomallei-and-burkholderia-thailandensisbiofilms 